\title{
Data and Artificial Intelligence for Better and
} Intelligent Regulation

\author{
Manuel Cabugueira ${ }^{1}$ \\ Universidade Lusófona
}

\section{I) Initial thoughts: the whys and the whats}

Contemplating the end of the XX century and in the dawn of the new one, it is clear that markets, private initiative and the freedom of choice are the champions for economic growth, technological development, innovation and, therefore, welfare. Having said that, it is also clear that markets' dynamics are not without failures and, more striking, that the success of a decentralized economy is closely dependent on centralized decision making processes. Markets work and will continue to work as the natural ecosystem for private initiative and freedom of choice, the engines of efficiency, but they are and will continue to be structured on top of centralized decision making institutions, both firms and the government.

Since the contributions of Coase in the "nature of the firm ", the "whys" and the "whats" on the existence of a firm are sufficiently clarified. Conversely, the discussion on the role of governments has been open to more controversy. Should there be public intervention? What are, or should be the motivation for an intervention? Should there be a limit to public intervention? Should it exercise more or less control on resource allocation? Should there be a requirement to justify an intervention?

\footnotetext{
1 Professor at the School of Economic Sciences and Organizations at the Universidade Lusófona de Humanidades e Tecnologias, researcher of the Legimpact project and collaborator of CIDEEFF.

${ }^{2}$ R.H. Coase, "The Nature of the Firm", Economica, New Series, 4, no. 16 (1937): 386-405.
} 
ULP Law Review | Revista de Direito da ULP

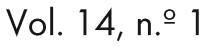

doi: 10.46294/ulplr - rdulp.v14i 1.7469

There is extended literature on these topics, motivating academic and political debate ${ }^{3}$. Following this literature it is interesting to notice that the discussion has taken a different path during the last decades. The initial debate on regulation or deregulation was left behind and replaced for a discussion on the quality of regulation. Accepting that the "invisible hand" of rivalry and private initiative may not be sufficient to guarantee efficiency and intra and inter-generational equity, the question is how and if the "visible hand" is able to do it better.

Supporting this new question there is a conjecture and an evidence $e^{4}$ a conjecture that markets fail but regulation also fails; and the evidence that, even though regulation creates benefices, it also raises costs and inefficiencies that will impact on citizens, firms the public administration. Therefore, public intervention has to be thought, designed, implemented and monitored in such a way that it guarantees a positive contribution to welfare, i.e., public intervention requires a demonstration that positive impacts will outweigh the expected costs. This approach demands an evidence-based approach to regulation meaning that policy making should be supported by information on expected or observed impacts.

In this paper we discuss the challenges that are raised by this approach to regulation and how the new tools of data technologies and artificial intelligence provide answers to some of the more relevant difficulties. It's a first reflection supported on a literature revision: we start by reviewing the concept and the difficulties that are faced by an evidence-based regulation, what are the Better Regulation programs and the importance of the impact assessment tool (II); we then discuss the contribution of data science and artificial intelligence for regulation (III); we condude with a reflection on how this new solutions can help to regulate better (IV).

\footnotetext{
${ }^{3}$ For a discussion on the foundations of regulation see, for example, R. Noll, Economic perspectives on the politics of regulation, in Handbook of Industrial Organization, edited by R. Schmalensee, R. Willig, Volume 2, Cp. 22 (Elsevier, 1989): 1253-1287; A. Ogus, Regulation: Legal Form and Economic Theory (Oxford: Hart Publishing, 2004), ISBN 1841135305; C. Sunstein, After the Rights Revolution: Reconceiving the Regulatory State (Harvard University Press, 1990), ISBN 9780674009097; R. Baldwin, M. Cave, and M. Lodge, Understanding Regulation: Theory, Strategy, and Practice (Oxford University Press, Oxford, 2011).

${ }^{4}$ For an initial discussion see R. H. Coase, "The Problem of Social Cost", The Journal of Law and Economics, 1, no. 3 (1960): 1-23.
} 
ULP Law Review | Revista de Direito da ULP

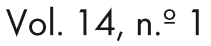

doi: 10.46294/ulplr - rdulp.v14i1.7469

\section{II) Evidence-based regulation - to regulate better}

After the privatisation and liberalization movement that occurred during the final decades of the last century, and the consequent debate on regulation, deregulation and reregulation, the focus has shifted to the quality of regulation. The Better Regulation programs that started to be adopted throughout the European countries and by the European Union and in other developed and developing countries are the practical output of this effort. ${ }^{5}$

A "Better Regulation" agenda embodies a regulatory effort that is simultaneously an objective and also a process. ${ }^{6}$ On one perspective, to have "better regulation" is to be able to respond to different challenges. First, regulatory drafts should improve in quality, being simpler, clear, providing legal certainty. Second, the measures that are adopted should be SMART (Specific, Measurable, Achievable, Realistic and Time-limited) ${ }^{7}$, and fit for purpose, in the sense that they should be adequate and proportional to the public policy objectives, not creating unnecessary burdens for citizens and firms. Third, regulation should also be fit for future, and this is a two folded objective: regulation should be flexible, so that it can adapt to new realities and to social end technological evolutions; it should be innovation driven, promoting the transmission of knowledge and avoiding the creation of barriers to

\footnotetext{
${ }^{5}$ We follow the view of Radaelli and Meuwes (2009), that Better Regulation is a meta-policy that provides the tools for a reform of the regulatory process and not as an alternative regulatory approach as proposed by Hansen and Pedersen (2006). As they explain: "whilst deregulation and re-regulation can be conceptually compared in a meaningful way, alternative regulation is of a different category altogether. The latter term refers to techniques of regulation. Instead, the other two terms denote an increase or decrease in 'regulationfree' space for economic actors. More importantly still, BR does not have an unequivocal identity of its own or an acquired conceptual status. It is an umbrella term that is used in policy contexts for a set of structural regulatory policy measures, at best a way of mediating deregulation and re-regulation and at worst an empty political catch phrase." (C. Radaelli and A. Meuwase, "Better Regulation in Europe: Between Public Management and Regulatory Reform," In Public Administration 87, no. 3 (2009): 639-654. We like to believe that it is more than a "catch phrase".

For a general discussion on Better Regulation see, Mandelkern Group, Mandelkern Group on Better Regulation, Final Report, 13 November 2001; European Commission, Better Regulation for better results An EU agenda, COM(2015) 215 final, European Commission, Strasbourg, 2016, OECD, Better Regulation Practices across the European Union; OECD Publishing, Paris, 2019; J. Wiener, "Better Regulation in Europe", Current Legal Problems, 59 (2006): 447-518.

${ }^{6}$ W. Hiller, "Impact Assessment and European Added Value work during the eighth legislative term, 20142019". European Parliamentary Research Service - briefing (2019).

7 UK HM Treasury, "The green book: central government guidance on appraisal and evaluation" (2020).
} 
ULP Law Review | Revista de Direito da ULP

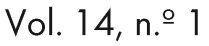

doi: 10.46294/ulplr - rdulp.v14i1.7469

innovation. Finally ${ }^{8}$, it should be resilient, preparing society and the economy to react and respond to disruptive shocks.

On another perspective, to "better regulate" also means to implement a regulatory process that should be more efficient and effective. A regulatory process that is no longer viewed as a linear sequence of independent stages but rather a cycle of interconnected steps that feed from one another reinforcing themselves. These interconnected steps will contribute to what might be a virtuous regulatory cycle that includes six phases: $1^{\text {st }}$ planning, $2^{\text {nd }}$ legislative draffing, $3^{\text {rd }}$ adoption, $4^{\text {th }}$ implementation, $5^{\text {th }}$ monitoring, and $6^{\text {th }}$ revision. These phases are implemented successively and circularly, and are supported by two fundamental pillars: the production of information to assist an evidence-based decision making process and the participation of stakeholder (stakeholder engagement).

In the background of the regulatory cycle there will be a fundamental relation between the policy decision-maker and the stakeholders that are directly or indirectly affected by regulation. The participation of citizens and businesses throughout the regulatory cycle increases transparency and accountability ${ }^{10}$ and allows for a better understanding of their needs and the impacts they support. This approach to the end user reflects a concern with the effectiveness of the regulation and also with its value for money, i.e., if the burdens supported in implementation will be justifiable and proportionate and, in that sense, efficient. This is a fundamental change in the way regulation is developed. The focus is no longer only on the "ifs" and "whys" of correcting a market failure and promoting welfare, but includes a new level of concern on the efficiency of the process demanding for a cost \& benefit analysis approach to support intervention.

\footnotetext{
${ }^{8}$ This is an objective that reflects the time when this article is being written, making clear that economic and social development may be affected by disruptive events, like a worldwide pandemic, that are uncontrollable. ${ }^{9}$ Following the best practices as proposed by the European Commission [European Commission, "Better Regulation Guidelines", SWD (2017) 350, Commission Staff Working Document, Brussels, 7 July 2017], the European Court of Audits (European Audit Court, "Ex-post review of EU legislation: a well-established system, but incomplete"), or the OECD [OECD, "Behavioural Insights and Public Policy: Lessons from Around the World" OECD Publishing, Paris (2017)].

${ }^{10}$ For a discussion on the contribution of information and performance base regulation to the quality of democracy view, C. Pollitt, "Performance Information for Democracy: The Missing Link?", Research Article, AGE Publications (London), January 1 (2006), and the discussion on Radaelli and Meuwes, 2009, 20.
} 
ULP Law Review | Revista de Direito da ULP

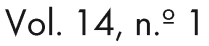

doi: 10.46294/ulplr - rdulp.v14i1.7469

To enforce this new perspective, in each phase, the public decision maker should reach out to the relevant stakeholders, whether by formal processes of public hearings or by direct or indirect informal contacts. Stakeholders are now seen as "'end users' of regulation" that are close to be "treated as 'customers" will also face costs when complying with new rules and obligations. They will inform on market and regulatory failures, on their needs and impacts borne, on the effectiveness of public intervention and they may also contribute to decrease uncertainty and information asymmetries.

Information becomes fundamental throughout the regulation cycle, and the rule is to support any decision on evidence regarding its impacts both expected and observed. This is the foundation of an evidence-based regulation that focuses on the impacts, the outputs and on the measurement and quantification of results "instead of "just trusting the doctor $^{\prime \prime \prime \prime 2}$. To produce information, the regulatory process uses the impact assessment tool that can be developed in two moments: at the beginning of the cycle, providing ex-ante evidence on the expected impacts, and at the end of the cycle, informing on the ex-post results. $^{13}$

The ex-ante impact assessment exercise supports the first three phases on the regulatory cycle (1st planning, 2nd legislative drafting, 3rd implementation), by informing the decision maker on the expected impacts of its intervention. It will provide decision makers with information on the economic and non-economic impacts or their decisions allowing for a cost \& benefit analysis of each measure that is being considered ${ }^{14}$. The final

\footnotetext{
${ }^{11}$ Radaelli and Meuwes, 2009, 15.

${ }^{12}$ Ibidem.

13 For more information om impact assessment visit the dedicated internet page by OECD https://ec.europa.eu/info/law/law-making-process/planning-and-proposing-law/better-regulation-why-andhow/better-regulation-guidelines-and-toolbox/better-regulation-toolbox en (visited on the 20/12/20202) and read OECD, Handbook for Undertaking Regulatory Impact Analysis (RIA), 2008, OECD Publishing, Paris, https:/www.oecd.org/gov/regulatory-policy/44789472.pdf. Also visit the European Commission Tool Box for regulation, https://ec.europa.eu/info/law/law-making-process/planning-and-proposing-law/betterregulation-why-and-how/better-regulation-guidelines-and-toolbox/better-regulation-toolbox en (visited in 20/12/2020). Also, see Andrea Renda, Impact assessment in the UE the state of the art and the art of the state, Center for European Policy Studies, Brussels, 2006.

${ }^{14}$ The requirement to support public intervention by demonstrating that the benefits outweigh the costs, was introduced in the USA in 1976 (Executive Order No. 11,949 of 31 December 1976), it was them transferred
} 
ULP Law Review | Revista de Direito da ULP

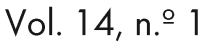

doi: 10.46294/ulplr - rdulp.v14i1.7469

decision, which is necessarily up to the legislative body, will be political, so the information provided by the impact assessment aims to support the process and not to favor more or less regulation. ${ }^{15}$

At the end of the cycle, a second moment of evaluation is needed (ex-post impact assessment) to evaluate the performance of the regulation. The objective will be to answer the following questions: Is the intervention efficient and effective? Does it generate unintended or indirect impacts? Does it contribute to the political objective initially identified by increasing welfare? Is there a need to reinforce, rethink or modify the intervention? For a more comprehensive evaluation of a political area, a "fitness check" would provide information on how several related legislative acts have contributed to a political objective. Fitness checks are particularly well-suited to identify overlaps, inconsistencies, synergies and the cumulative impacts of related regulation. ${ }^{16}$

The effort to follow the legislative process with the production of information and the engagement of stakeholders (seen as end users) brings the public decision maker closer to the private experience, introducing a decision making practice that is driven by evidence, performance and learning ${ }^{17}$. These are challenges that can be meet only if some elements are in place $^{18}: 1^{\text {st }}$ high level support and commitment; $2^{\text {nd }}$ the responsibilities for

to other countries lice Australian, Canada, UK and other European countries. For a review of the impact assessment history, see Andrea Renda, Impact assessment in the UE (cit.).

${ }^{15}$ This perspective is made clear by the European Commission ["Better regulation for better results - An EU agenda", COM (2015) 215 final, Strasbourg, 19.5.2015: "Better regulation is not about "more" or "less" EU legislation; nor is it about deregulating or deprioritising certain policy areas or compromising the values that we hold dear: social and environmental protection, and fundamental rights including health - to name just a few examples. Better regulation is about making sure we actually deliver on the ambitious policy goals we have set ourselves"].

${ }^{16}$ On evaluation and fitness checks that support the "evaluate first principle" view the European Commission, Befter Regulation toolbox, assessed in December 2020

${ }^{17}$ The focus on evidence-based regulation brings the Better Regulation agenda close to the discussions on the necessity to introduce a managerial like perspectives on public intervention that is defended by New Public Management (NPM) and its perspective on institutional reform. For a development of this idea see the literature on the New Public Management (NPM): C. Pollitt, The Essential Public Manager (Buckingham: Open University Press, 2003) and Pollitt, C. and G. Bouckaert, Public Management Reform: A Comparative Analysis (Oxford: Oxford University Press, 2000). For a discussion on the relation between this concept and Better Regulation see Radaelli and Meuwes, 2009, 15.

${ }^{18}$ This "rules", follow the work done by the OECD, during the last decades in gathering and disseminating best practices on regulation and, in particular, on impact assessment (see OECD, Best Practice Principles for Regulatory Policy (Paris: OECD Publishing, 2020); OECD, Determinants of quality in regulatory impact analysis (Paris: OECD Publishing, 2016). To understand the OECD work on regulation it is essential to read 
ULP Law Review | Revista de Direito da ULP

Vol. 14, n. .1

doi: 10.46294/ulplr - rdulp.v14i1.7469

implementing and executing are well established; 3th there are internal competences, and continuous training, for executing impact assessment; $4^{\text {th }}$ the analytic tools in use are consistent and flexible, so that they can adapt to the objectives; $5^{\text {th }}$ data collection strategies are clear and transparent; $6^{\text {th }}$ evaluation efforts are proportionate and well directed; $7^{\text {th }}$ impact assessment is integrated into the regulatory cycle; $8^{\text {th }}$ the results are communicated in a transparent manner allowing for scrutiny and accountability; $9^{\text {th }}$ the public and stakeholders are intensively involved; $10^{\text {th }}$ there is a solid commitment for evidence-based decision making.

Even though these elements seem evident, the striking fact is that they match the difficulties that practitioner's find when implementing impact assessment, which are: $1^{\text {st }}$ lack of political support and commitment because the process is time consuming and may jeopardise political goals and the effectiveness of the intervention; $2^{\text {nd }}$ lack of technical expertise in the public sector; $3^{\text {rd }}$ lack of data (in quality and quantity), and the resistance to create data centres and to implement auto-learning mechanisms; $4^{\text {th }}$ lack of flexibility and capacity to adapt creating regulatory lags and regulatory delays; $5^{\text {th }}$ lack of transparency which undermines accountability and hampers stakeholder engagement ${ }^{19}$. All the previous will put in stress the capacity for regulation to have quality, to be fit for purpose, fit for future and resilient.

\section{III) Data Science, artificial intelligence and regulation}

During the last centuries markets witnessed an increase in human productivity supported by a transition from muscles to mechanical, then to computation, to networks and now to cognitive powers. These were the critical changes that sustained the four

the OECD, Recommendation of the Council on Regulatory Policy and Governance, 1012, OECD Publishing. On the challenges and dangers of use of best practices on regulation see C. M. Radaelli, How Context Matters: Regulatory Quality in the European Union (2004).

${ }^{19}$ For an empirical discussion on this difficulties see. P. Caroll,"Does regulatory impact assessment lead to better policy?", Policy and Society, 29(2) (2010): 113 and 122 and T. Kurniawan et al, "Regulatory impact assessment and its challenges: An empirical analysis from Indonesia", Kasetsart Journal of Social Sciences, 39(1) (2018): $105-108$. 
ULP Law Review | Revista de Direito da ULP

Vol. 14, n. .1

doi: 10.46294/ulplr - rdulp.v14i 1.7469

industrial revolutions that occurred since the middle XIX century, including the one that we are now living. ${ }^{20}$

The fourth revolution, that is now underway, is driven by megatrends that "leverage the pervasive power of digitalization and information technology" and created physical, digital and biological impacts. Schwab", the sponsor of the "fourth revolution" concept, talks about 21 shifts that will constitute main changes during the next years. We draw attention for two of them.

First (shift 11), the use of big data technologies by government "to automate their current programs and deliver new and innovative ways to service citizens and customers". As Schwab underlines, "big data will enable better and faster decision making in a wide range of industries and applications". Contributing to "real time decision making, reducing complexity, improving efficiency and cost saving". This changes will not come without potential negative impacts on jobs, privacy, and will raise doubts over accountability and trust. ${ }^{22}$

A second shift to take into account (shift 13), relates to the expected role of artificial intelligence (Al) in support of decision making through automated learning cycles. Al "can learn from previous situations to provide input and automate complex future decision processes, making it easier and faster to arrive at concrete conclusions based on data and past experiences". ${ }^{23}$ It will allow for more rational, data-driven decisions, less bias and the "removal of 'irrational exuberance"".

Both "shifts" point to important changes in decision making processes that have been well explored by private deciders and should, also, be at the centre of policy decision making modernization. The automated learning processes, not only, facilitate decision making, but also, reduce bias and arbitrary introducing more robust and consistent decision practices.

\footnotetext{
${ }^{20}$ See K., Schwab, The Fourth Industrial Revolution: what it means, how to respond (New York: World Economic Forum, (rown Business, 2016).

${ }^{21}$ Ibidem, Appendix.

22 lbidem, 228.

${ }^{23}$ Ibidem, 235.
} 
ULP Law Review | Revista de Direito da ULP

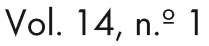

doi: 10.46294/ulplr - rdulp.v14i1.7469

In support of this tendency, the European Commission's science service, the Joint Reseach Center (JRC), proposes a new perspective in the relation between Science and Politics. A "Science for Policy 2.0" model, developed in three directions: $1^{\text {st }}$ ceasing the demarcation between science and policy; $2^{\text {nd }}$ putting "science at the service of complex, transversal policy issues, rather than keeping it in comfortable, well-defined, scientific boxes"; $3^{\text {rd }}$ helping "policymaking departments to deal with the deluge of data, information and knowledge which is now available"; and $4^{\text {th }}$ "improve our futureoriented competences and tools". 24

For the third line of development, Craglia et al. ${ }^{25}$ take on the subject of Big Data and Al contribution to the modernization of the entire policy cycle "from anticipation to design, implementation, monitoring and assessment". They recognize the potentialities of combining the two technologies, making regulation more adaptive to a fast-changing world and more attentive to the "silent and overlooked groups". With a more dynamic access to evidence, policy making will be both more flexible and focused in the individuals "addressing their needs, expectations and perceptions".

Big Data contributes to this change providing the tools to process a bigger volume of data (big volume), in a close to real-time approach (big velocity), with the capacity to inform on heterogeneous information (big variety) $)^{26}$. Turning into $\mathrm{Al}$, they propose that it is time for an "algorithmic governance", a new approach to regulation that will be, not only, more flexible, but also more adaptive with "short feedback loops" and interventions that are sensitive to evidence on their impacts, i.e. a regulation that learns and is supported by algorithms that learn (machine learning and deep learning, which are steps forward within the IA methodologies ${ }^{27}$ ). Both Big Data and Al (in its many developments) may allow for

\footnotetext{
${ }^{24}$ Forward by Vladimír Sucha to the JRC "Science for Policy Handbook" (2020): Pages xiii-xiv.

${ }^{25}$ M. Craglia, J. Hradec, and X., Troussard, "The Big Data and Aritificial Intelligence: Opportunities and Challenges to Modernise the Policy Cycle", in Science for Policy Handbook, edited by Vladimír Šucha and Marta Sienkiewicz, cap. 9, (Elsevier, 2020): 96-103.

${ }^{26}$ D. Laney, 3D Data Management: Controlling Data Volume, Velocity, and Variety (META Group, February 6, 2001).

${ }^{27}$ For a definition of Al and the alterative algorithmic approaches see Banzhaf, W. et al, "Guidelines: From artificial evolution to computational evolution: a research agenda". Nat Rev Genet. 2006 Sep;7(9) or Davenport, T. (2018) "From analytics to artificial intelligence", Journal of Business Analytics, 1:2, 73-80,
} 
ULP Law Review | Revista de Direito da ULP

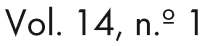

doi: 10.46294/ulplr - rdulp.v14i1.7469

more flexible, adaptive and responsive policies that might be more efficient and even more equitable.

Notwithstanding this advantages, the "'algorithmic' governance" will not come without difficulties and transparency, accountability and the respect for individual privacy may become an issue. On the one side, decisions will be taken on the basis of rules that might not be accountable or understood and privacy protection rules may question the legality of the information that supports a "needed based" ${ }^{\prime 28}$ approach. On the other, more evidencebased interventions, that uses targeted information, may improve transparency and accountability of policy-makers regarding macro and micro objectives and promises made.

On the same line of argument as the JRC, the UK Government Office for Science (UKGOS) highlights the opportunities and implications of Al for future decision making. They focus on the potentialities of these tools to increase productivity at the public decision level following the experience and the example of private initiative. ${ }^{29}$

In the private sector Al has been used in legal activities to reduce the burdens (both physical resources and time) of searching for relevant and interrelated information in large sets of texts, to expedite due diligence and to support risk assessment. In commerce and insurance, this tools have been used to identify behavior patterns and risks. It is clear the Al will not replace human intelligence, its role will rather be to provide a helping hand in processing huge amounts of data and overcoming complex and repetitive analytical tasks that are resource consuming or just outside of the analytical capabilities of individuals. Al is integrated as part of a process where the analysis and the decisions will continue to demand the active involvement of the human intellect that will have more time for productive activities, to identify new paths or new innovative solutions. ${ }^{30}$

\footnotetext{
${ }^{28}$ Important to note that the "needed based" intervention is also related to the "liberal paternalistic" perspective introduced by the "nudge" to policy making. On the impact and challenges of behavioural insights applied to policy making see the ground breaking work by R. Thaler and C. Sunstein, Nudge: improving decisions about health, wealth and happiness (Penguin Books: 2008), for a practical approach see the work developed at the European by Lourenço et al on Behavioural insights applied to Policy.

${ }^{29}$ UK Government Office for Science, Arrificial Intelligence: Opportunities and Implications for the Future of Decision Making, Nov., 2016, hittps://www.gov.uk/government/publications/artificial-intelligence-anoverview-for-policy-makers

${ }^{30} \mathrm{lbidem}, 10$ and 11.
} 
ULP Law Review | Revista de Direito da ULP

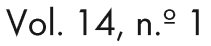

doi: 10.46294/ulplr - rdulp.v14i 1.7469

The UKGOS proposes that the different data science technics could support the government in four areas: increase the efficiency of public services; informed public decision makers reducing errors and frauds; raise transparency in public decision making; and, provide information on groups that will be targeted by public intervention. The potentialities of the new data technologies are particularly emphasized in what regards the identification of patterns and stress points and on "statistical profiling" that uses past data to predict the likely actions or qualities of different groups. The use of machine learning techniques will support better risk assessment, more targeted interventions and better identification of threats. Again, the benefits don't come without challenges and this evolution raise ethical questions in the use of information. ${ }^{31}$

Still on the use of big data technologies, Van Ooijen ${ }^{32}$ et al., challenge the Government to "move from a focus on the external publication of data towards a highly adept public service that is skilled in the recognition and use of data as a core component of a highly functioning state and the effective design and delivery of its activities." The authors are aiming to the concept of a "data-driven public sector" brought forward by the OECD to refer to a Government "which recognises data as an asset, integral to policy making, service delivery, organisational management and innovation". This new Government would bring more efficiency to public intervention "promoting evidence-led policy making and databacked service design as well as embedding good governance values of integrity, openness and fairness in the policy cycle".

The data-driven government is expected to explore big data in three consecutive moments. First, as an "anticipatory government", using data both to produce forecasts about future trends and needs and to develop alternative future scenarios in the framework of foresight analysis. Second, as an evidence-driven government, supporting the design and delivery of public policies on evidence that reflect the effective need of users and not on "assumptions and beliefs of public servants". Third, and still as an evidence-driven

\footnotetext{
${ }^{31}$ Ibidem, 14 to 16.

${ }^{32}$ C. Van Ooijen, B. Ubaldi, and B. Welby, A datodriven public sector: Enabling the strategic use of data for productive, inclusive and trustworthy governance (OECD, Working Papers on Public Governance, 2019), htrps://dx.doi.org/10.1787/09ab162c-en.
} 
ULP Law Review | Revista de Direito da ULP

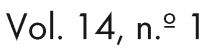

doi: 10.46294/ulplr - rdulp.v14i 1.7469

government, developing an evidence-based post implementation performance analysis, including monitoring and the revision of the initial options.

Through the policy making cycle, data helps: to understand the setting and to develop the planning; it then informs the decision to support the design; to finally produce evidence on the results, the effectiveness and efficiency of the intervention, that will feedback to a new cycle. At any moment of this cycle, data on stakeholders' reactions and behaviors will allow for a "need led approach" that should be more efficient, effective and responsive to social changes. The engagement with stakeholders will allow for a "granular analysis of policy problems, producing the insights that lead to contextual variations in policy design and implementation, which can boost policy effectiveness, lessen unnecessary burden on citizens and allow government to better target scarce resources" ${ }^{\prime \prime}$

\section{IV) Final thoughts: the obvious confirmation, the "hows" and the stresses}

We ended the section on better regulation talking about the factors that are fundamental to the quality of impact assessment and, therefore, for the improvement of a better regulation program. Those same factors matched the main difficulties that are faced by policy decision-makers when they strive to develop quality regulation that is fit for purpose, fit for future and resilient.

Taking into consideration all the opportunities presented on the last section regarding the use of data and Al, it is obvious the way they may help to respond to the difficulties and challenges presented to the better regulation efforts.

In what concerns regulatory resilience, the aim is to be prepared for unexpected and unperceived futures. This demands a good understanding of future scenarios and possible risks and uncertainties. Data analysis and learning algorithms may answer to this challenges providing analytical tools that are, simultaneously, able to handle large amounts of information and exploit auto-learning systems that produce and process alternative results. 
ULP Law Review | Revista de Direito da ULP

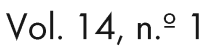

doi: 10.46294/ulplr - rdulp.v14i 1.7469

Fit for future, is all about flexibility and the capacity to react and adapt. The private sector knows how to be prepared for the future and has learned how to adapt and take advantage of innovation cycles. They know how to identify and respond to the necessities of users, how to create or influence those necessities and how to bring new research and developments into the market. They have the resources, both technical and human, and the incentive to do so (the survival in the market depends on it). Does the public decisionmaker have the same incentives, pressures and capacities? We made the point about the political commitment for better regulation and the concurrent resistance to adopt a new, more demanding, decision process. On the one side, policy makers will be willing to improve the quality of public intervention, its efficiency and equity, understanding the value of quality over urgency. On the other side, the argument will be made that politicians have a democratic mandate to implement a plan in a given time-frame and should not be obstructed by procedures (like impact assessments) that are lengthy and resource consuming . Besides this political discussion, there are also the technical difficulties that come from the regulatory lag - time lag between the adoption of a new theological by the market and the regulatory adaptation to it, and regulatory delay - time lag between the creation of a new technology and the regulatory green line for its application. In both cases, a new data driven and algorithmic driven regulation could help to increase flexibility, providing automated learning cycles and reducing the response times.

Finally, to be fit for purpose and to have quality regulation depends, mostly, on proportionality and evidence-based decision making. This is the core of a data driven governance that demands expertise, quality data and transparency of processes. New data technologies and artificial intelligence may provide the needed tools to support each stage of the regulatory cycle while making the process more transparent, engaging and accountable.

How to put these tools into practices? It also demand's institutional, professional and human flexibility. To achieve this, regulation should turn itself into innovative ways of approaching the design, implementation and control that may require experimentation. A first line of answers might be found on the regulatory learning processes associated with sandboxes, innovation hubs and experimentation testbeds. Will there be "stresses"? Yes 
ULP Law Review | Revista de Direito da ULP

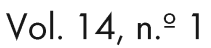

doi: 10.46294/ulplr - rdulp.v14i1.7469

there will! Regarding ethical aspects, privacy and technical capacity. These will be the next challenges for academic consideration and for practitioners. For now it seems that we can conclude that an evidence-based regulation should evolve to also be data-driven.

\section{Bibliography}

Allemanno, A. "Stakeholder engagement in regulatory policy." In Regulatory Policy in Perspective: A Reader's Companion to the OECD Regulatory Policy Outlook. Paris: OECD Publishing, 2015. https://doi.org/10.1787/9789264241800-en

Allio, L. "Improving Regulatory Governance through stakeholder engagement." In Improving Regulatory Governance: Trends, Practices and the Way Forward. Paris: OECD Publishing, 2017. https://doi.org/10.1787/9789264280366-en

Baldwin, R., Cave, M., and Lodge, M. "Understanding Regulation: Theory, Strategy, and Practice". Oxford: $\quad$ Oxford $\quad$ University 2011. https://D0l:10.1093/acprof:osobl/9780199576081.001.0001

Banzhaf W., Beslon G., Christensen S., Foster J. A., Képès F., Lefort V, Miller J. F., Radman M., Ramsden J. J. "Guidelines: From artificial evolution to computational evolution: a research agenda". Nat Rev Genet., 2006. https://doi.org/10.1038/nrg1921

Caroll, P. "Does regulatory impact assessment lead to better policy?" Policy and Society 29, no. 2, (2010): 113-122. https://doi.org/10.1016/i.polsoc.2010.03.009

Craglia, M., Hradec, J. and Troussard, X. "The Big Data and Artificial Intelligence: Opportunities and Challenges to Modernise the Policy Cycle." In Science for Policy Handbook, edited by Vladimír Šucha and Marta Sienkiewicz, 96-103. Elsevier (2020). https://doi.org/10.1016/C2018-0-03963-8. 
ULP Law Review | Revista de Direito da ULP

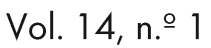

doi: 10.46294/ulplr - rdulp.v14i1.7469

Coase, R. H. "The Nature of the Firm." Economica, New Series 4, no. 16 (1937): 386-405.

https://doi.org/10.2307/2626876.

Coase, R.H. "The Problem of Social Cost". The Journal of Law and Economics 1, no. 3 (1960): 1-23. https://doi.org/10.1086/466560.

Davenport, Thomas H. "From analytics to artificial intelligence". Journal of Business Analytics 1, no. 2 (2018): 73-80. DOI: 10.1080/2573234X.2018.1543535

European Court of Audits. "Ex-post review of EU legislation: a well-established system, but incomplete". Special Report, no. 16, 2018.

https://www.eca.europa.eu/Lists/ECADocuments/SR18 16/SR BETTER REGULATION_EN .pdf

European Commission. "Better Regulation Guidelines". SWD (2017) 350. Brussels: Commission Staff Working Document, 7 July 2017. https://ec.europa.eu/transparency/regdoc/rep/10102/2017/EN/SWD-2017-350-F1-ENMAIN-PART-1.PDF

European Commission. "Better Regulation for better results - An EU agenda". COM (2015) 215 final. Strasbourg: European Commission, 2016. hitps://eur-lex.europa.eu/legalcontent/EN/TXT/PDF/?uri $=$ CELEX: 52015DC02158from $=E N$.

European Commission. "Better regulation toolbox". hittps://ec.europa.eu/info/law/law-makingprocess/planning-and-proposing-law/better-regulation-why-and-how/better-regulationguidelines-and-toolbox/better-regulation-toolbox en (accessed 20/12/2020).

Lourenço, J, Ciriolo, E., Vieira de Almeida, R. and Troussard, S. "Behavioural insights applied to Policy" (EU Science Hub Report, 2016). https://doi.org/10.2760/707591. 
ULP Law Review | Revista de Direito da ULP

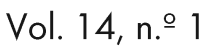

doi: 10.46294/ulplr - rdulp.v14i1.7469

Foss Hansen, H. and Holm Pedersen, L. "The Dynamics of Regulatory Reform." In Autonomy And Regulation: Coping With Agencies in the Modern State, edited by T. Christensen and P. Lægreid, 328-355. Cheltenham: Edward Elgar, 2006. https://doi.org/10.1111/i.1467$9299.2008 .7515 . x$

Hiller, W. "Impact Assessment and European Added Value work during the eighth legislative term, 2014-2019". European Parliamentary Research Service - briefing, 2019.

Kurniawan, T. Muslim, M and Sakapurnama, E., et. al. "Regulatory impact assessment and its challenges: An empirical analysis from Indonesia." Kasetsart Journal of Social Sciences 39, nol (2018): 105-108. https://doi.org/10.1016/i.kjss.2017.12.004.

Laney, D. "3D Data Management: Controlling Data Volume, Velocity, and Variety". META Group, 2001.

Mandelkern Group. "Mandelkern Group on Better Regulation, Final Report" (13 November 2001). Available at http://ec.europa.eu/smart-regulation/better regulation/documents/ mandelkern report.pdf.

Noll, R. "Economic perspectives on the politics of regulation." In Handbook of Industrial Organization, edited by R. Schmalensee, and R. Willig, Vol 2,1253-1287. Elsevier, 1989. https://doi.org/10.1016/S1573-448X(89)02010-8.

OECD. Better Regulation Practices across the European Union. Paris: OECD Publishing, 2019. hitps://doi.org/10.1787/9789264311732-en.

OECD. Behavioural Insights and Public Policy: Lessons from Around the World. Paris: OECD Publishing, 2017. http://dx.doi.org/10.1787/9789264270480-en 
ULP Law Review | Revista de Direito da ULP

Vol. 14, n. .1

doi: 10.46294/ulplr - rdulp.v14i1.7469

OECD. Best Practice Principles for Regulatory Policy. Paris: OECD Publishing, 2020. hitps://doi.org/10.1787/7a9638cb-en.

OECD. Recommendation of the Council on Regulatory Policy and Governance. Paris: OECD Publishing, 2020. hitpp://dx.doi.org/10.1787/9789264209022-en.

OECD. Determinants of quality in regulatory impact analysis. Paris: OECD Publishing, 2016. hitps://www.oecd.org/gov/regulatory-policy/42047618.pdf.

OECD. Handbook for Undertaking Regulatory Impact Analysis (RIA). Paris: OECD Publishing, 2008. hitps://www.oecd.org/gov/regulatory-policy/44789472.pdf.

Ogus, A. Regulation: Legal Form and Economic Theory. Oxford: Hart Publishing, 2004.

Pollitit, C. "Performance Information for Democracy: The Missing Link?"' Research Article. London: AGE Publications, January 1, 2006. https://doi.org/10.1177/1356389006064191.

Pollitt, C. The Essential Public Manager. Buckingham: Open University Press, 2003.

Pollitit, C. and Bouckaert, G. Public Management Reform: A Comparative Analysis. Oxford: Oxford University Press, 2000.

Radaelli, C. and Meuwase, A. "Better regulation in Europe: between public management and regulatory reform." In Public Administration, 87(3), 639-654, September 2009. hitps://doi.org/10.1111/i.1467-9299.2009.01771.x.

Radaelli, C. M. "How Context Matters: Regulatory Quality in the European Union" (2004). Available from www.psa.ac.uk/cps/2004/Radaelli.pdf. 
ULP Law Review | Revista de Direito da ULP

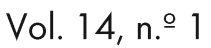

doi: 10.46294/ulplr - rdulp.v14i1.7469

Renda, A. Impact assessment in the UE the state of the art and the art of the state. Brussels: Center for European Policy Studies, 2006.

Schwab, K. The Fourth Industrial Revolution: what it means, how to respond. New York: World Economic Forum, Crown Business, 2016.

Šucha, V. "Forward to Science for Policy Handbook." In Science for Policy Handbook, edited by Vladimír Šucha and Marta Sienkiewicz, pages xiii-xiv. Elsevier, 2020. https://doi.org/10.1016/C2018-0-03963-8.

Sunstein, C. "After the Rights Revolution: Reconceiving the Regulatory State." Harvard University Press, 1990. ISBN 9780674009097.

Thaler, R. and Sunstein, C. Nudge: improving decisions about health, wealth and happiness. New York: Penguin Books, 2008.

Van Ooiien, C, Ubaldi, B and Welby B. "A data-driven public sector: Enabling the strategic use of data for productive, inclusive and trustworthy governance." OECD Working Papers on Public Governance, 2019. https://dx.doi.org/10.1787/09ab162c-en.

UK Government Office for Science. "Artificial Intelligence: Opportunities and Implications for the Future of Decision Making. " November 2016.

https://www.gov.uk/government/publications/artificial-intelligence-an-overview-forpolicy-makers.

UK HM Treasury. "The green book: central government guidance on appraisal and evaluation", 2020. https://assets.publishing.service.gov.uk/government/uploads/system/uploads/attachment data/file/938046/The Green_Book_2020.pdf. 
ULP Law Review | Revista de Direito da ULP

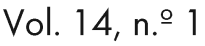

doi: 10.46294/ulplr - rdulp.v14i1.7469

Wiener, J. "Better Regulation in Europe". Current Legal Problems 59 (2006): 447-518.

hittps://scholarship.law.duke.edu/faculty scholarship/1586. 